\title{
8
}

\section{Object-oriented modelling and analysis of business processes}

\author{
K. Mertins, H. Edeler, R. Jochem, J. Hofmann \\ Fraunhofer Institute of Production Systems \\ and Design Technology (IPK) Berlin \\ Pascalstraße 8-9, D-10587 Berlin, Germany, \\ Phone: ++49/(0)30/39006 234, Fax: ++49/(0)30/3911037 \\ joerg.hofmann@ipk.fhg.de
}

\begin{abstract}
Many problems within enterprises appear as a consequence of both organizational and technological issues. The integration of processes regarding aspects of dynamics and concurrency during decision making is a key element for achieving flexibility. Changed tasks and timeframes have to be reflected by restructured process chains.

To improve competitiveness, all efforts are traditionally concentrated on optimization of single functions - the enterprise is subdivided into a number of separate functions, which are easier to overview and control. This introduces a number of "interface" problems in organization and optimization of single functions at the expense of the manufacturing process and the organization as a whole.

The integration of separated functions and the optimization of business processes require a higher degree of transparency within the organization. In consideration of the complex relationships - looking on the manufacturing enterprise as a network of functions - modelling methods have to be applied, to support, to ease, and to systematize planning and integration of functions to business processes and to describe the related organizational structure. Suitable methods secure a common understanding of business processes and provide mechanisms for structuring the required information about processes and organization.

The authors describe a methodology for integrated modelling of business processes, related organsational structures, and information based on an object-oriented approach which is in discussion at ISO TC184/SC5/WG1 and CEN TC310/WG1 for standardisation. Examples of industrial application for different areas and a supporting modelling tool prototype are presented.
\end{abstract}

\section{Keywords}

Integrated enterprise modelling, object-oriented modelling, business process, standardisation, modelling tool 


\section{INTRODUCTION}

In the nineties enterprises face a higher pressure of time and pressure to succeed at global markets, increasing competition, shorter product life cycles and, related to this, a higher flexibility in all areas. The market demands additional product differentiation exactly meeting customer needs, advance of technological level of products, shortening of both product development and order troughput times, advance of delivery time, and advance of product quality. To fulfil these requirements the enterprise of the future is characterized by:

- flexibility of production resources;

- automation of manufacturing and assembly;

- interconnection of all manufacturing systems, organizational processes, and decision centres.

Therefore, a higher transparency of enterprise organization and processes is required. Flexible automation presupposes a clear structure of the organization of information and material flows. Commercial just as organizational and technical matters have to be considered. The common understanding of all participants about the objectives and the core processes of the enterprise as well as about project goals is essential for the efficiency of both planning and development of business process organization.

In the following, the method of Integrated Enterprise Modelling (IEM) is presented. IEM uses the object-oriented modelling technique for modelling business processes, related organizational structures and required information systems as well. It provides a model for planning and optimizing the processes and organizational structures within the enterprise.

Models developed according to the IEM method give a transparent representation of planning information and therefore, are the basis for discussion between project participants. For evaluating the variety of planning information and description requierements, it allows different views on one consistent model.

IEM models provide the means to precisely assign the value of planning goals, like improvements in time, cost, or quality, to each business process and resource and, by that, to optimize the process organization.

\section{OBJECT-ORIENTED MODELLING}

\section{The Approach}

Object-oriented techniques are broadly used for the development of applications in various areas. The main advantage of this approach is the entirety of data and functions operating on these data. Provided with the powerful inheritance mechanism it yields models which are more stable and easier to maintain than those based on other modelling approaches (Coad and Yourdon, 1990). However, methods providing an entire, object-oriented approach for enterprise modelling are not seen so far.

In order to utilize it's advantages and to provide a comprehensive and extendable enterprise model, the IEM method uses the object-oriented modelling approach, thus allowing the integration of different views on an enterprise in one consistent model and the easy adaptation of the model to changes within the enterprise (Coad and Yourdon, 1990; Mertins and Jochem, 1993; Süssenguth, 1991). 


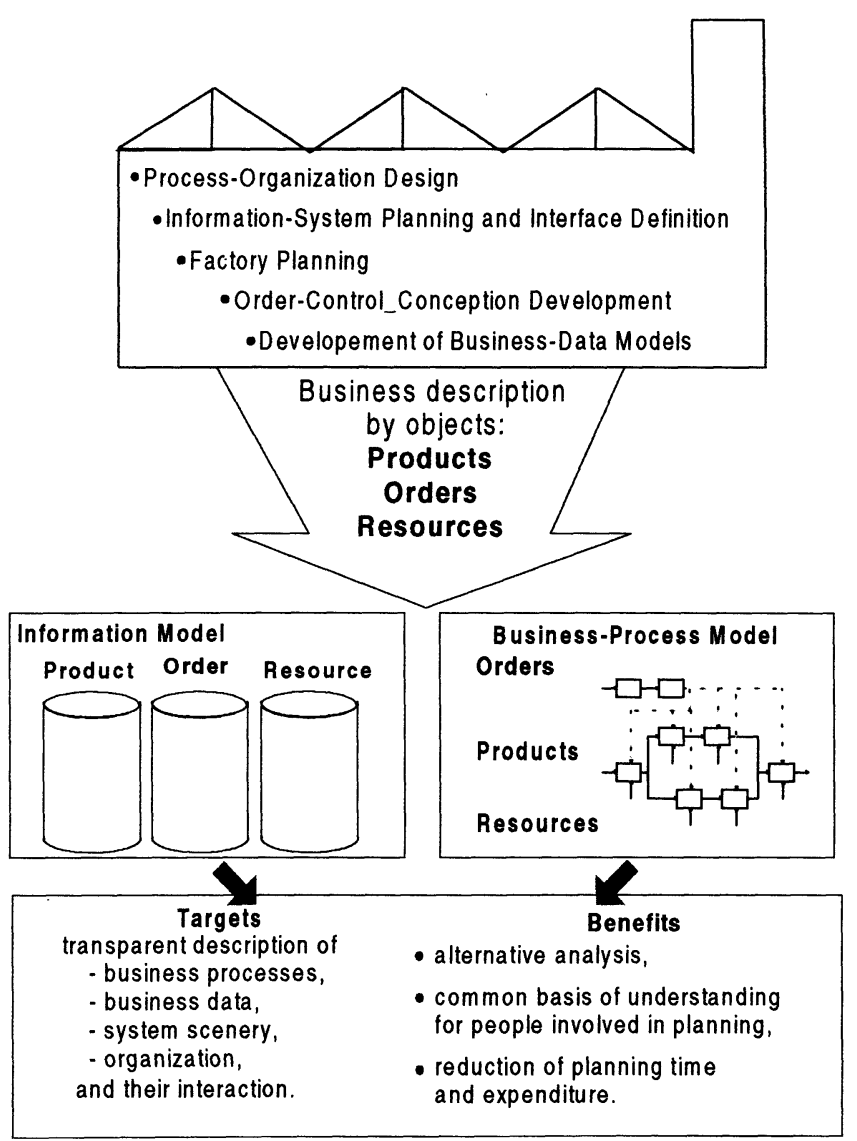

Figure 1 Views of the enterprise model.

\section{Generic classes of objects}

The generic classes Product, Resource, and Order form the basis of Integrated Enterprise Modelling for developing models from the user's point of view. They will be specialized according to the specifics of an individual enterprise (ISO TC 184/SC5 N 148; Süssenguth, Jochem, Rabe and Bals, 1998; Mertins, Süssenguth and Jochem, 1991). Each generic class prescribes a specific generic attribute structure, thus defining a frame for describing the properties and the behaviour of objects of it's subclasses (cf. Figure 4). Real enterprise objects will be modelled as objects of these subclasses.

Required enterprise data and the business processes, i.e. the tasks referring to objects, are structured in accordance to the object classes (see below). Furthermore, the relations between objects are determined. The result is a complete description of tasks, business processes, enterprise data, production equipment, and information systems of the enterprise at any level of detail (Spur, Mertins and Jochem, 1993; Mertins, Süssenguth and Jochem, 1994). 
The model kernel comprises two main views. The tasks, which are to be executed on objects, and the business processes are the focal point of the Process Model View, whereas the Information Model View primarily regards the object describing data (Figure 1). Thus, the kernel of the enterprise model consists of the data and process representations of classes of objects. The views are interlinked by referring to the same objects and activities, although they represent them in different ways, levels of detail and context. Any view on the model can be derived from this standardized model kernel. Additional features can be tied to the kernel if necessary.

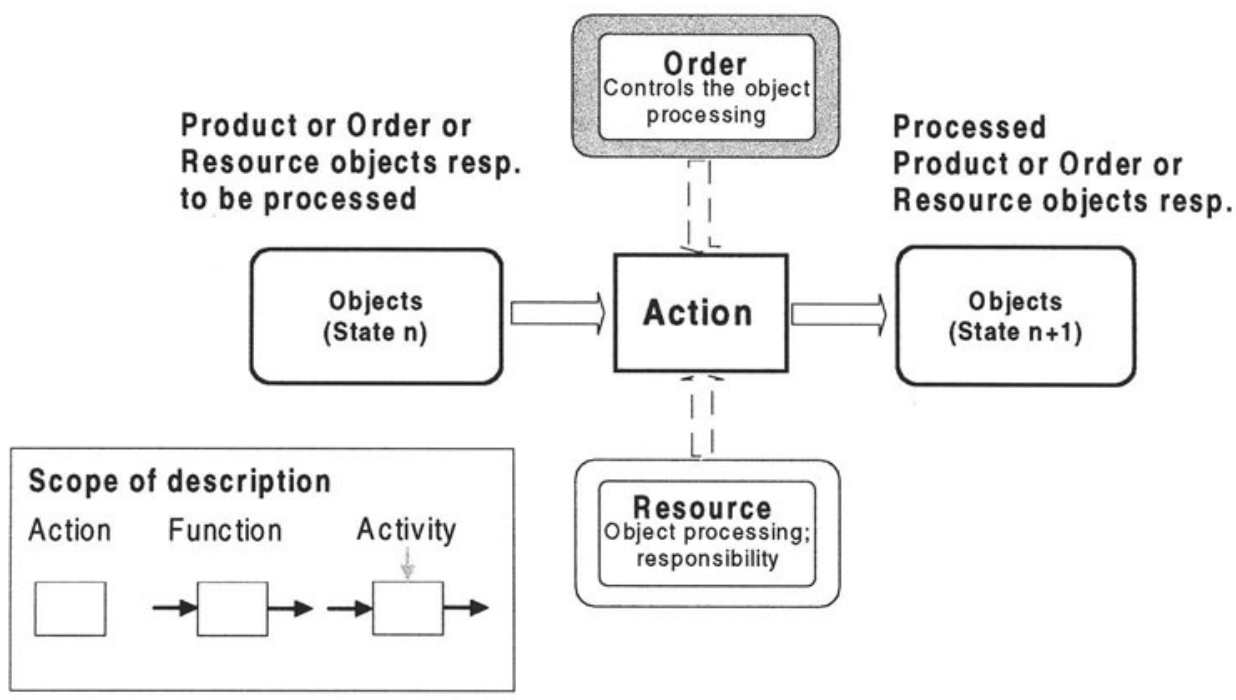

Figure 2 Interactions of Objects described by Generic Activity Model.

\section{Business Processes as Interactions of Objects}

Everything that happens in a manufacturing enterprise as part of some business process can be described by activities. In general, activities process and modify objects which were classified above as Products, Orders, and Resources. The execution of any activity requires direct or indirect planning and scheduling, it is executed by Resources owing the needed capability. The IEM method suggests three levels of describing the essentials of an activity.

- The Action is an object-independent description of some work or business, a verbal description of some task, process step, or procedure.

- The Function describes the processing of objects as a transformation from one determined (beginning) state to another determined (ending) state.

- The Activity specifies the Order controlling the execution of the Function and the Resource(s) being in charge of executing the Function. 
Figure 2 graphically represents the Generic Activity Model. The beginning and ending states are connected with the action rectangle by arrows from left to right. The controlling of the activity is represented by an Order state description and a dashed vertical arrow from top; the required or actually assigned capability for executing the function is represented by a Resource state description and a dashed vertical arrow from bottom.

The Generic Activity Model represents the processing of objects of Product or Order or Resource classes respectively indicating the object interactions at processing. The related organizational structure is described by specific Resource classes along with their interrelations (see Chapter 5).

Using special concatenating constructs (cf. Figure 3), Actions, Functions, and Activities are combined to represent business processes. The decomposition and aggregation of processes is supported as well. The IEM modelling constructs of the Process Model View are shown in Figure 3.

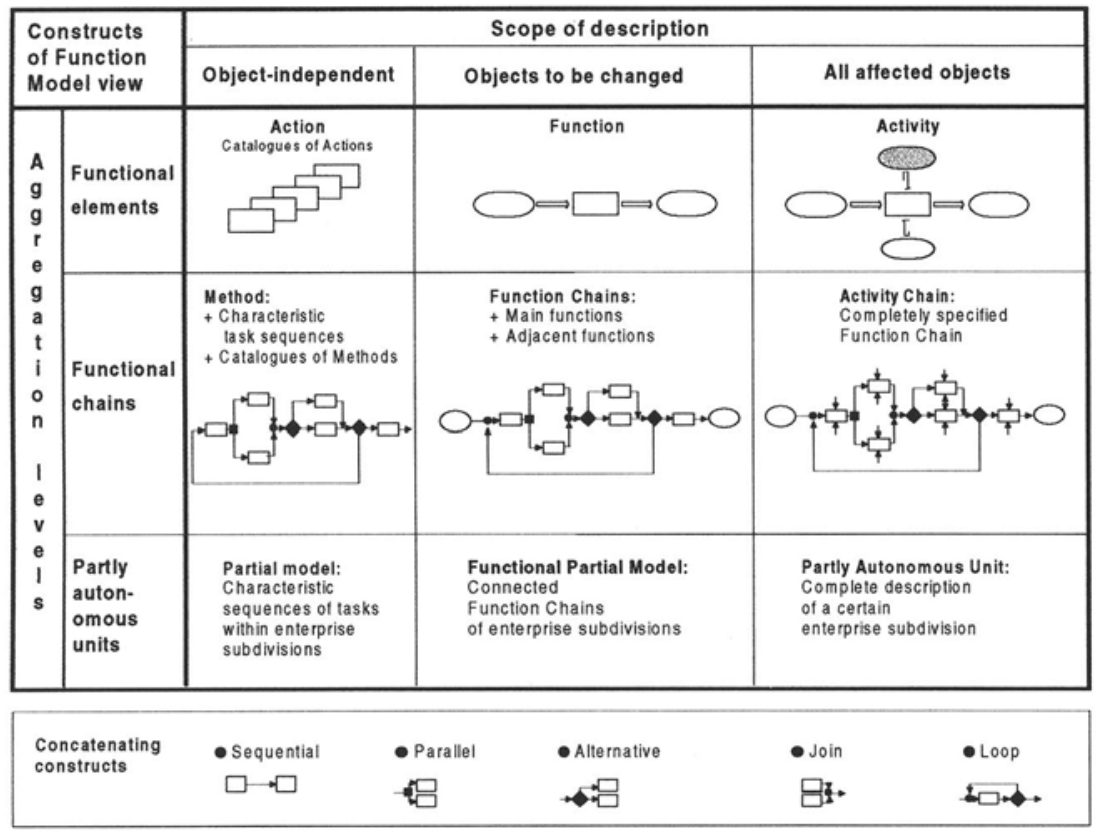

Figure 3 Constructs of the Process Model View.

Product classes represent the main results of the whole enterprise process - the products. Resource classes represent all means, including organizational units, being necessary for carrying out any activity in the enterprise. Order classes represent planning and control information. Figure 4 represents the attribute schemes of the generic classes (Spur, Mertins and Jochem, 1993; Mertins, Süssenguth and Jochem, 1994; Mertins and Jochem, 1992). 

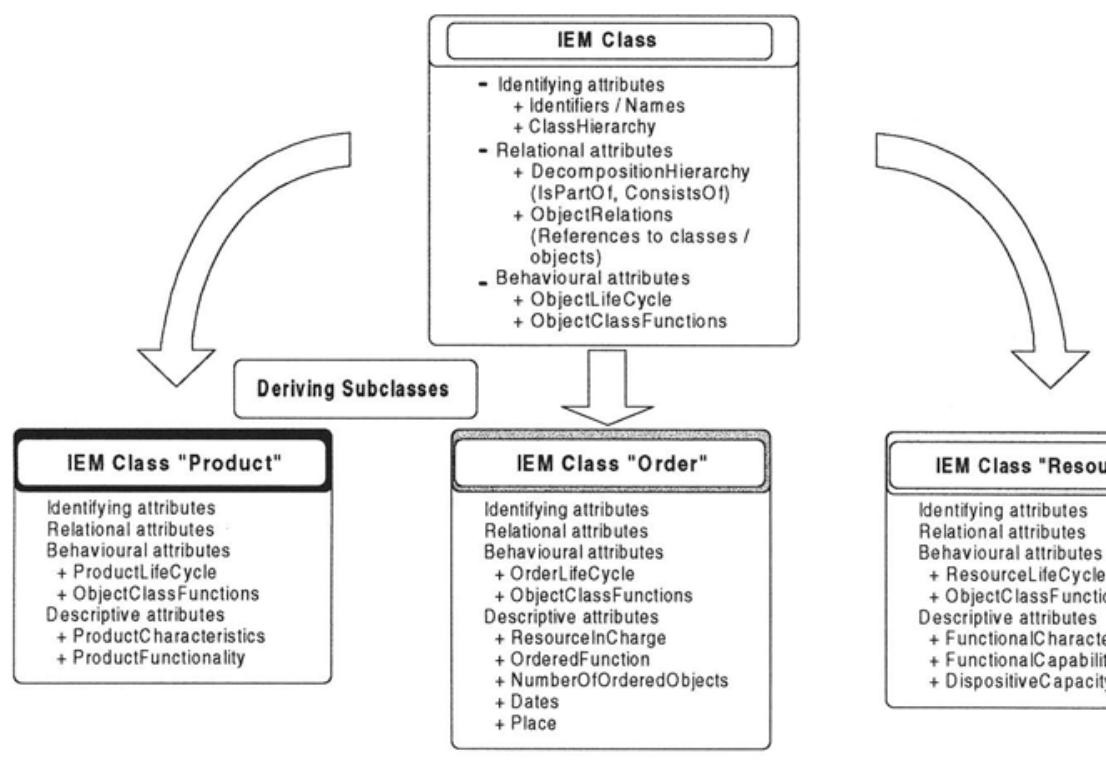

Figure 4 IEM object class attributes.

\section{MODELLING PROCESS}

\section{Business Process Modelling}

The description of enterprise processes starts with the analysis of the actual situation, normally applying a top-down procedure. Business processes along with the respective classes of objects to be processed are the starting point for modelling a certain part of the enterprise. This part is delimited in a first step concerning e.g. Products and respective "ordering" with regard to the main task, required resources and the interfaces to the environment as well. The main task and objects of the application area are described by that (Mertins and Jochem, 1992 and 1993; Süssenguth, 1991).

The products have to be identified as subclass instances of the IEM class Product and the business processes have to be modelled according to these products, independently of organizational structures (Figure 5).

Next, resources and controlling orders have to be identified for each function of the defined enterprise processes.

To obtain more detail, business processes of generation, processing and supply of orders and resources as well as of processing of sub-objects of the products should be modelled. The network and the interdependencies of the business processes are described with the concatenating constructs of the IEM (Mertins, Süssenguth and Jochem, 1991, Mertins and Jochem, 1992). 
The development of particular business process models has to be extended by the order and resource flow, the analysis of concurrency of business processes and their mutual influence. For this purpose simulation and other methods should be applied.

\section{Information Modeling}

The collection and structuring of the data of all objects which were identified at modelling lead to a particular enterprise information model. For this purpose, a structuring frame for representing the relevant data is required.

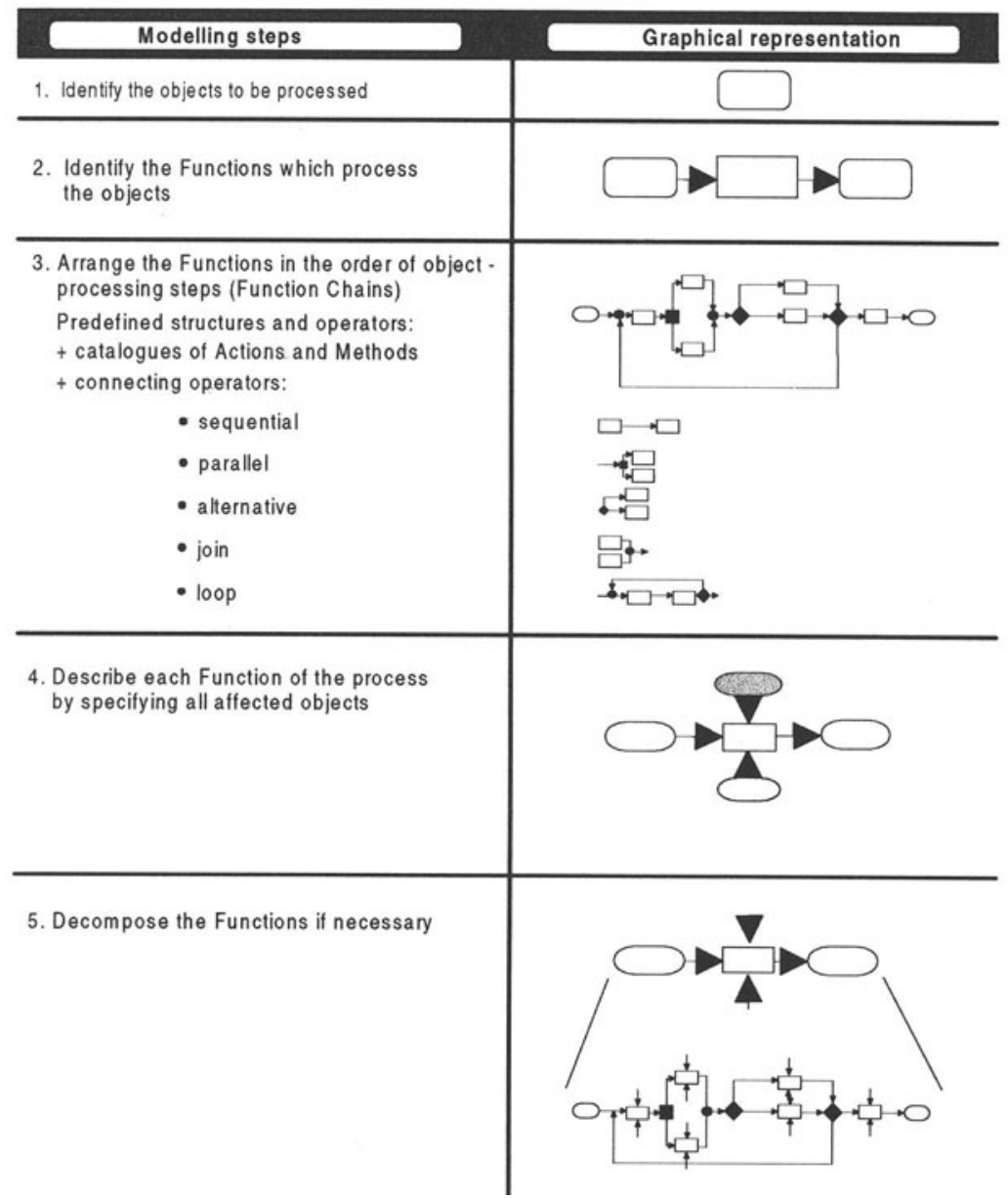

Figure 5 Modelling process. 
The differentiation of the generic classes of objects and their internal structure define the structure of the enterprise information model. Three interconnected submodels, the Product, Control and Resource models are defined. The internal structure of the submodels is represented by layers which enable a grouping of object data by different criteria.

Beside the aid for data structuring, the IEM data modelling provides the advantage of close relation to the application area by considering real world objects with regard to the generic classes. The independence of data of a specific information processing system secures the extendability and interchangeability of data between several systems. A particular enterprise information model will provide the preconditions for a general use of data bases and support the recognition of priorities at data exchange (Mertins and Jochem, 1993).

The first step for the development of a particular information model of an enterprise is the cataloguing of objects, their descriptive data and object relations in data dictionaries. Different kinds of lists were defined in the layers of the enterprise information model.

\section{INTEGRATION OF ORGANIZATIONAL STRUCTURES AND INFORMATION SYSTEM SUPPORT BY ADDITIONAL VIEWS}

Further aspects of modelling related to special purposes can be integrated as additional views on the model. Examples of such views are special representations of control mechanisms, organizational units and costs. The relevant properties of the additional views can be represented by deriving specific subclasses of the generic classes:

- Determination of class,specific attributes,

- determination of respective attribute values.

An example for the integration of additional views related to the special purpose of planning and introduction of CIM systems is shown by Figure 6.

The model kernel is the basis for developing application-oriented modelling constructs, views and partial models. Existing application-oriented classes, constructs, views, and models can be traced back to the main views of an enterprise model. Therefore, changes in business processes or in organization and their impact on information system support can be evaluated.

This example shows how the model kernel can be used and extended by representing additional subjects and views. In the same principle way, several other models can be integrated into an entire enterprise model (Süssenguth, 1991).

The scheme comprises eight layers, which represent the interlinked fields of design within the enterprise.

The layers "Functions" and "Data" represent the business process and the required information independently of technical solutions, i.e. the model kernel as presented above.

The layers "Application systems", "Data storage", "Network" and "Hardware" are the technical fields of information system planning related to the first two layers. 


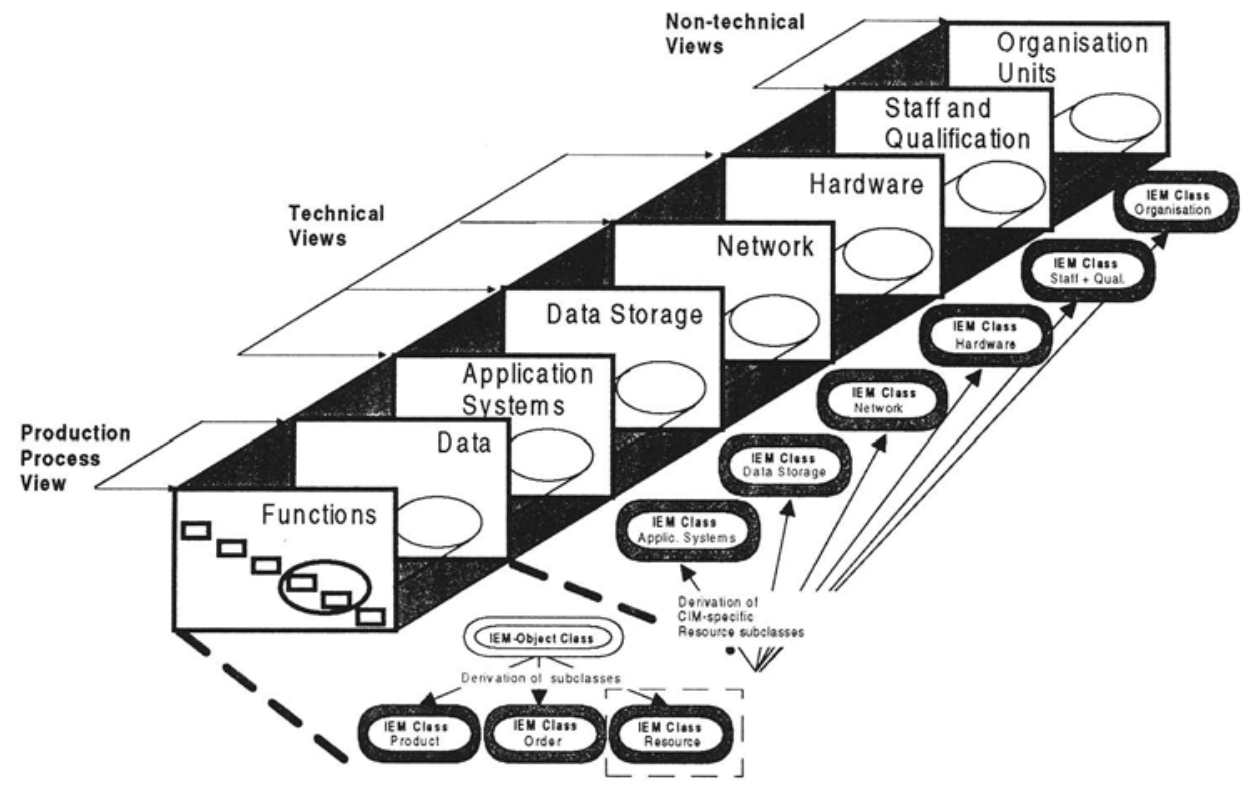

Figure 6 Views of Information System Support and Organization.

The layers "Organizational units" and "Staff and Qualification" are non-technical fields of design, which have to be considered simultaneously to the others. The tube across the layers illustrates their interrelations incorporated in the functions and data of the respective classes and objects.

Specific Resource subclasses have to be defined to represent additional views, like organization, with the respective properties (cf. Figure 4), (Mertins and Jochem, 1992).

The right choice of the level of detail is important for the modelling effort and benefit. For the task of information system planning, an overall, not too detailed modelling of a number of enterprise areas should be preferred.

The modelling of sub-classes leads to data, function and system interfaces, which are indicators of obstructions for integration. Interfaces in that sense have to be avoided. Therefore, alternatives within each view have to be worked out and evaluated against their potential benefit (Süssenguth, 1991).

\section{APPLICATION AREAS}

The described method of Integrated Enterprise Modelling is suitable for various planning and structuring measures in enterprises. It covers the aspects of material and information flows as well. In addition to the systematization of planning in a certain project, the benefits of applying the method are obtained from the reusability of the models for further projects with different tasks (Spur, Mertins and Jochem, 1993). Examples for the application of the IEM as an accepted description method in industrial projects are the following: 
- Ascertainment of kernel processes in distributed enterprise structures of rail vehicle manufacturers;

- analysis and ascertainment of layout structures for the organization of production preparation and execution in distributed enterprises of rail vehicle manufacturers;

- presentation of potentials for saving time and costs by improved information system at order execution (Figure 7);

- development of a CIM architecture and an order control concept in a mechanical engineering plant (Figure 8);

- concept of interfaces between head office and decentralized production plants in distributed company structures;

- reorganization and development of a modern rail vehicle production.
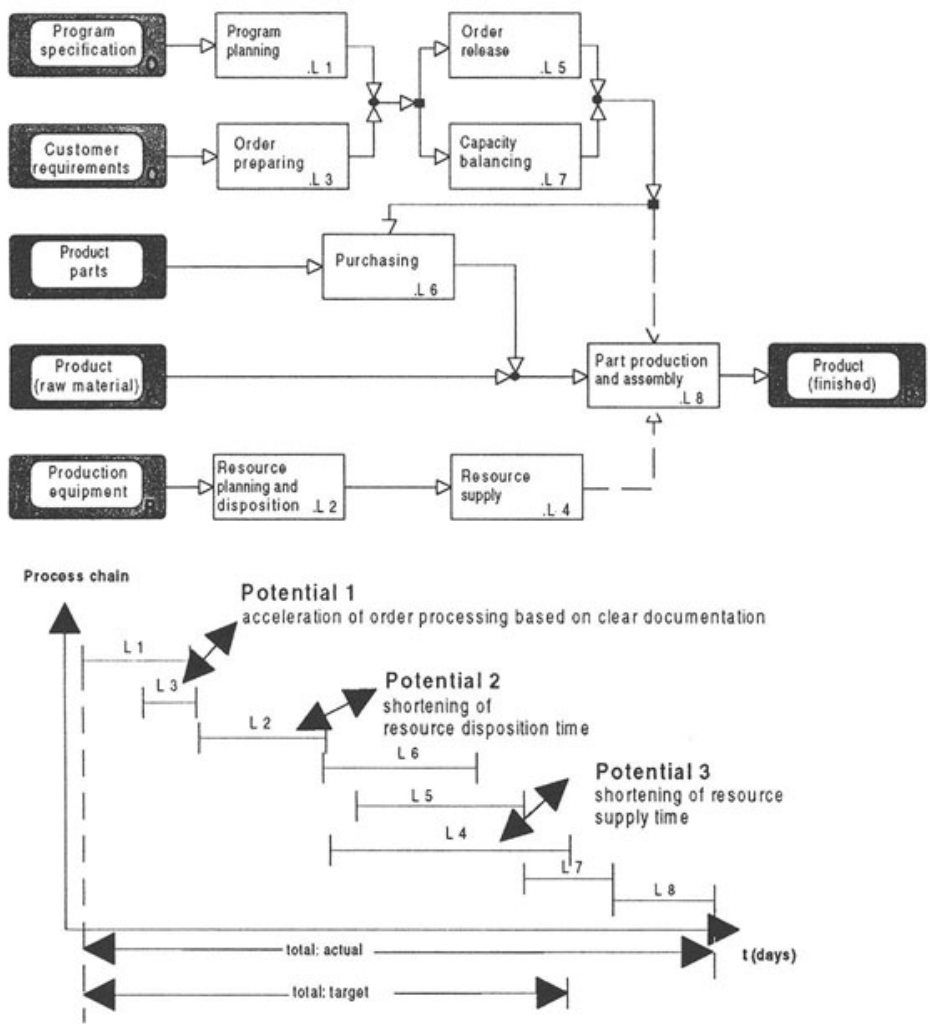

Figure 7 Derivation of potentials to save time at order processing. 


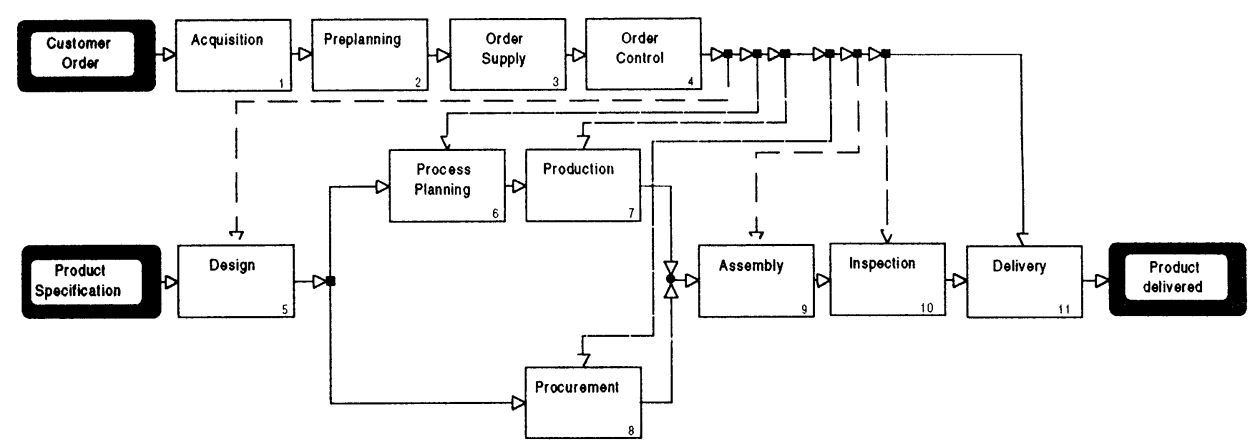

Figure 8 Entire enterprise process.

\section{MODELLING TOOL}

The use of the described method for enterprise modelling is only efficient in connection with a modelling tool. A PC-based verison, which supports the method, is available (Figure 9).

It is based on Windows 3.1 platform and uses Windows standard. The development of the graphical notations (diagram technique) of the user-interface was supported by a special commercial software package. The logics and the application rules of the method are implemented in $\mathrm{C}++$ independently of the supporting software via a special programming interface (Spur, Mertins and Jochem, 1993). The following modelling tasks are supported by the functionality of the tool:

- Classification of products, orders and resources of the enterprise;

- hierachy of business processes;

- description of product, order and resource structures;

- generation of documents;

- rapid model construction by predefined model structures and navigation facilities;

- support of different user views.

The Tool is used in industrial projects of IPK as well as in internal projects of industrial and consulting companies. 


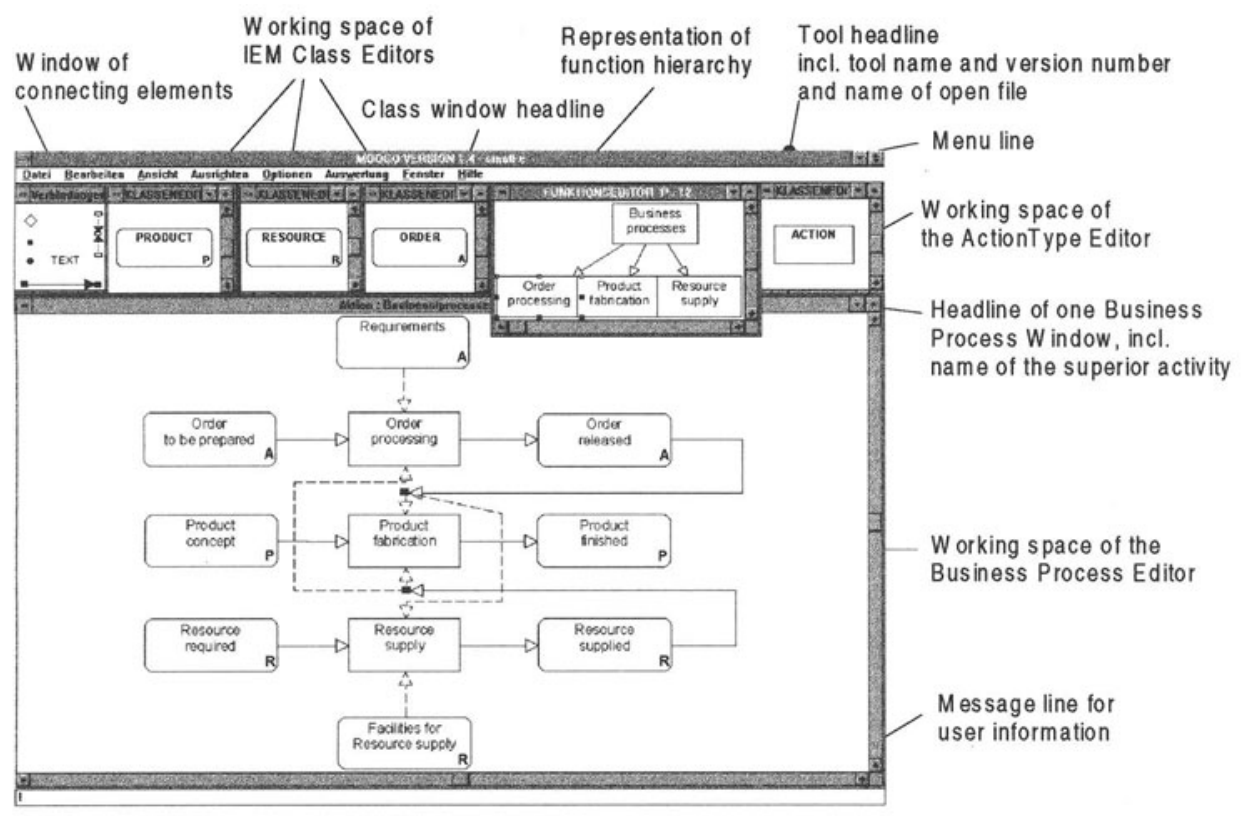

Figure 9 Tool user interface.

\section{RELATION TO OTHER MODELLING METHODS}

There exist a number of methodologies for enterprise modelling with their own purposes and advantages. In (Mertins, Süssenguth and Jochem, 1994) a detailed analysis of several modelling methods was conducted. Here we mention only ICAM/IDEF and SADT as examples of function-oriented methods. Generally speaking, the main topic of these methods are data processing functions, data and functions are represented in separate models loosely tied via the names of data entities.

Besides the well-known difficulties at systems design, implementation and maintenance, the application of these methods for business process re-engineering faces the problem that, starting with function analysis, one rather "copies" the existing organizational structure than to analyze the (object-related) nature of processes. Thus, for the task of process re-engineering these methods are useful but not optimal.

CIMOSA is another major methodology for enterprise modelling. CIMOSA models, based on a process modelling concept, support the complete enterprise life cycle of enterprise engeneering and operation. CIMOSA provides a reference architecture for particular enterprise architectures, supporting the complete enterprise life cycle and providing different views on the model.

The method of Integrated Enterprise Modelling (IEM) views an enterprise starting from the production process in it's entirety and the resulting requirements. The aim of IEM is to build a comprehensive (conceptual) enterprise model as an aid for analyzing and re-engineering 
business processes, and as a platform for developing and integrating various CIM applications independently of a particular implementation environment.

Recently, representatives of CIMOSA Association and Working Group Quality-oriented Enterprise Modelling (part of German QCIM Project) elaborated a comparison paper of CIMOSA and IEM modelling constructs in order to assist European standardization of enterprise modelling constructs at CEN TC310/WG1 (CEN TC310/WG1 (Architecture) N41).

This comparison demonstrates transferability (on the basis of constructs) and complementarity (considering details related to intended use) of the two approaches. Transferability means that it is possible to construct a transformation which maps a CIMOSA model to an IEM model and vice versa. Complementarity expresses the fact that, for each method, some parts are elaborated with more detail related to the intended use.

So, the common efforts of CIMOSA and IEM hopefully will pave the way towards an useful standard of modelling constructs being conducive to enterprise integration and to meet the challenges of recent economical development.

\section{REFERENCES}

CEN TC310/WG1 (Architecture) N41, Comparison CIMOSA - IEM Modelling Constructs. June 1994.

Coad, P. and Yourdon, E.: Object Oriented Analysis.

Yourdon Press/Prentice Hall, Englewood Cliffs, New York, 1990.

Flatau, U.: Digital's CIM-Architecture, Rev. 1.1.

Digital Equipment Corporation, Marlboro, MA U.S.A., April 1986.

Harrington, J.R.: Understanding the Manufacturing Process. Key to Succesful CAD/CAM Implementation. Marcel Dekker, inc: 1984.

ISO TC 184/SC5 N 148, Technical Report: Reference Model for Shop Floor Production, Part 1.

Mertins, K. and Jochem, R.: An Object-oriented Method for Integrated Enterprise modelling as a Basis for Enterprise Coordination, International Conference on Enterprise Integration Modeling Technology (ICEIMT), Hilton Head (South Carolina), US Air Force-Integration Technology Division, June 92.

Mertins, K. and Jochem, R.. Planning of Enterprise-Related CIM-Structures. In: Proceedings of 8th International Conference CARS and FOF. Metz; France, 17.-19. August 1992.

Mertins, K. and Jochem, R.: Integrierte Unternehmensmodellierung - Basis für die Unternehmensplanung. DIN-Tagung. April 1993.

Mertins, K., Süssenguth, W..and Jochem, R.: Integration Information Modelling. In. Proceedings of Fourth IFIP Conference on Computer Applications in Production and Engineering (CAPE '91). Bordeaux, France. Elsevier Science Publisher B.V. (North Holland). 
Mertins, K., Süssenguth, W. and Jochem, R.: Modellierungsmethoden für rechnerintegrierte Produktionsprozesse (Hrsg.: G. Spur). Carl Hanser Verlag. München, Wien. 1994.

Spur, G., Mertins, K. and Jochem, R.: Integrierte Unternehmensmodellierung. Beuth Verlag. Berlin. 1993.

Süssenguth, W., Jochem, R., Rabe, M. and Bals, B.: An Object-oriented Analysis and Design Methodology for Computer Integrated Manufacturing Systems. Proceedings Tools ' 89 , November 13-15, 1989, CNIT Paris/France.

Süssenguth, W.: Methoden zur Planung rechnerintegrierter Produktionsprozesse.

Dissertation. Berlin 1991.

\section{BIOGRAPHY}

Dr.-Ing. Kai Mertins,

Born in 1947, Education in Electro-Mechanic, Study of Electrical Engineering at the Engineering School of Hamburg. Several Industrial Experiences as Electrical Engineer. Study of Economical Engineering at TU Berlin. 1984 Doctoral Thesis at TU Berlin. Since 1982 Head of Department and since 1988 Director of the Division Systems Planning at the FraunhoferInstitute for Production Systems and Design Technology (IPK Berlin).

\section{Dipl.-Soz. Hermann Edeler,}

Born in 1955, Study of Social Sciences and Economics at University of Bielefeld and Free University of Berlin. Since 1986 researcher at IPK and since 1992 Head of Department Production Management, Division Systems Planning at the Fraunhofer-Institute for Production Systems and Design Technology (IPK Berlin).

\section{Dipl.-Ing. Roland Jochem,}

Born in 1962, Study of Mechanical Engineering at TU Berlin. Industrial Experiences as Mechanical Engineer. Since 1988 researcher and since 1991 Group Leader for Business Process Modelling at the Fraunhofer-Institute for Production Systems and Design Technology (IPK Berlin), Division Systems Planning.

\section{Dipl.-Math. Jörg Hofmann,}

Born in 1952, Study of Mathematics at the Donetsk State University (Ukraina). Experiences in basic and applied research. Since 1992 researcher at the Fraunhofer Institute of Production Systems and Design Technology IPK Berlin, Division Systems Planning. 